\title{
Effect on Microcystis aeruginosa inactivation by Manganese Copper Composited Algaecide
}

\author{
ZHAO Liang, LI Xing, LIANG Shuang, YANG Yan-ling \\ Key laboratory of Beijing for Water Quality Science and Water Environment Recovery Engineering \\ College of Architecture and Civil Engineering Beijing University of Technology \\ Beijing, China \\ E-mail: zlang1999@126.com
}

\begin{abstract}
Manganese copper composited algaecide (MCC) was prepared by permanganate and acid-soluble copper chloride. The effectiveness of MCC on Microcystis aeruginosa removal and the effective period of $M C C$ were studied, $p H$ influence on the water sample was inspected, and the feasibility of MCC as a new algaecide was discussed. The results showed that inactivation effect on Microcystis aeruginosa by MCC was obvious. Optimum ratio of copper reagent $A$ and manganese reagents $B$ was $0.5-1.5: 1$. Removal rate of turbidity, $O D_{420}$ and chlorophyll a were $67.82 \%, 77.98 \%$ and $97.04 \%$ respectively during 10 days of MCC dosing. MCC is a long effective period algaecide. Turbidity and chlorophyll a were reduced to $6.16 \mathrm{NTU}$ and $1.048 \mu \mathrm{g} \cdot \mathrm{L}^{-1}$, with removal rate of $77.4 \%$ and $99.48 \%$ after MCC dosing of 16 days. PH value of water samples was reduced with increased ratio of copper reagent within $M C C$. When composited ratio is $0.5-1.5: 1 \mathrm{pH}$ value is 7-8. This study laid the foundation for research and development of the new algaecide.
\end{abstract}

Key words- manganese copper composited algaecide; composited ratio; effective period; Microcystis aeruginosa; inactivation

\section{INTRODUCTION}

Eutrophication of lake and reservoir waters is increasingly serious. Algae especially Cyanophyta and Chlorophyta reproduce excessively to form a thick layer of indigo blue lake emission obnoxious odor. Algae in drinking water supply can cause significant disturbances including taste and odor, production of disinfection by-product (DBP), obstruction to coagulation, clogging of filter, and assimilable organic carbon (AOC) for biofilm growth [1-3]. Water Bloom occurrence frequent, which make serious damage to the aquatic ecology Balance system. In recent years, numerous studies reported that animal and human diseases and even death caused by algae pollution in many countries [4-6]. Over the last two decades, harmful algal blooms (HABs) occurred more frequently in China, well in line with global trend [7]. Ingrid and Jamie [8] pointed out that different degree eutrophication are existed in $53 \%, 28 \%, 48 \%$, and $41 \%$ respectively of lakes in Europe, Africa, North America and South America. 54\% of lakes in Asian Pacific Area are under eutrophic condition. Up to now, more than $60 \%$ of the lakes in China have been eutrophicated and suffered from HABs. Cyanobacterial Microcystis aeruginosa (M.A.) is one of the dominant species of fresh water-bloom [9]. The excessive growth of toxic M.A. greatly deteriorated the water quality [10], damaged lakes' natural

This work was funded by the Project 50778003 supported by National Natural Science Foundation of China functions, and even threatened the drinking water resources. It has become one of the top priorities in China to develop waterbloom control techniques that are safe, highly efficient and cost effective. The development of environmental and efficient algaecide and algae control technologies, in order to control eutrophication is one of the major environmental problems needed to be solved.

A variety of algae removal technologies are developed. Several approaches, such as chemical, mechanical and biological techniques, have been studied in HABs removal of seawater systems [7]. Chemical methods which can produce immediate results, e.g. chemical algaecide, are paid less attention recently, mainly because of their adverse effects on other organisms and the expedited release of microcystins [1112]. Research showed that [13] the algae had a strong absorption capacity on copper ions, which was an important reason that copper ion is used for algae removal. Copper sulfate, copper citrate, and other copper compounds are the most commonly used algaecide. A large number of reports showed that algae cells can be destroyed by copper sulfate [14]. Cell shell membrane damage may cause compounds or intracellular organic matter (IOM) into the bulk water resulting in of taste and odor release [15]. So the better strategy for algae control in water treatment would be removing algae cell intact without cell rupture.

It is not reported that copper chloride be used as algae removal, although as a material of making fungicides $\mathrm{Cu}_{2} \mathrm{OCl}_{2}$. The reason may be of poor water-solubility, but copper chloride can be dissolved in some specific solution, for example, dissolved in concentrated hydrochloric acid to produce $\mathrm{H}_{3} \mathrm{O}^{+} \mathrm{CuCl}^{2-}$, and with halide ions to increase cogeneration of complexing ion that dissolved in water. Permanganate is frequently used as preoxidant in high algaeladen water treatment, which are served as both algaecide and flocculant aid [16-19].

Permanganates are used as algaecide and disinfectant [2021 ], which can be provided a good effect on algae removal It is not reported that toxic and the harmful organic matters are produced during permanganate oxidation [16, 22]. Manganese copper compound algaecide is prepared by acid-soluble copper chloride and potassium permanganate in this study.

Microcystis aeruginosa is in general representative to the algae pollution of freshwater as study object. To study the 
performance of algae inactivation through the static simulated experiment, in order to lay the foundation for further study the mechanism of manganese copper compound algaecide on algae killing and practical application.

\section{MATERIALS AND METHODS}

\section{A. Experimental sample}

Microcystis aeruginosa was obtained from Institute of Hydrobiology, Chinese Academy of Sciences, and incubated in sterilized 250-mL glass flasks containing200-mL BG 11 medium at $25 \pm 1.5{ }^{\circ} \mathrm{C}$ under fluorescent light $(3000 \mathrm{~lx}, 12-\mathrm{h}$ light/12-h dark). The M. aeruginosa medium BG 11 medium component in table 1.

\begin{tabular}{|c|c|} 
Table 1 BG 11 Medium for Cyanobacteria \\
\begin{tabular}{|c|c|}
\hline Reagent & working solution/g/l] \\
\hline $\mathrm{NaNO}_{3}$ & 1.5 \\
\hline $\mathrm{K}_{2} \mathrm{HPO}_{4} \cdot 3 \mathrm{H}_{2} \mathrm{O}$ & 0.04 \\
\hline $\mathrm{MgSO}_{4} \cdot 7 \mathrm{H}_{2} \mathrm{O}$ & 0.075 \\
\hline $\mathrm{CaCl}_{2} \cdot 2 \mathrm{H}_{2} \mathrm{O}$ & 0.036 \\
\hline citric acid & 0.006 \\
\hline Ferric ammonium citrate & 0.006 \\
\hline EDTA (dinatrium-salt) & 0.001 \\
\hline $\mathrm{Na}_{2} \mathrm{CO}_{3}$ & 0.02 \\
\hline $\mathrm{A} 5+\mathrm{Co} \mathrm{solution}^{*}$ & $1 \mathrm{ml}$ \\
\hline distilled water & 919 \\
\hline
\end{tabular}
\end{tabular}

\begin{tabular}{|c|c|}
\hline \multicolumn{2}{|c|}{ * Composition of the A5 + Co solution } \\
\hline $\mathrm{H}_{3} \mathrm{BO}_{3}$ & $2.86 \mathrm{~g}$ \\
\hline $\mathrm{MnCl}_{2} . \mathrm{H}_{2} \mathrm{O}$ & $1.81 \mathrm{~g}$ \\
\hline $\mathrm{ZnSO}_{4} \cdot 7 \mathrm{H}_{2} \mathrm{O}$ & $0.222 \mathrm{~g}$ \\
\hline $\mathrm{CuSO}_{4} \cdot 5 \mathrm{H}_{2} \mathrm{O}$ & $0.079 \mathrm{~g}$ \\
\hline $\mathrm{Na}_{2} \mathrm{MoO}_{4} \cdot 2 \mathrm{H}_{2} \mathrm{O}$ & $0.390 \mathrm{~g}$ \\
\hline $\mathrm{Co}\left(\mathrm{NO}_{3}\right)_{2} .6 \mathrm{H}_{2} \mathrm{O}$ & $0.049 \mathrm{~g}$ \\
\hline distilled water & $1000 \mathrm{ml}$ \\
\hline
\end{tabular}

According to concentration of chlorophyll a, algae-laden water can be divided into Olipotrophication $\left(<25 \mu \mathrm{g} \cdot \mathrm{L}^{-1}\right)$, Mesotrophication $\left(<50 \mu \mathrm{g} \cdot \mathrm{L}^{-1}\right)$, Eutrophication) $\left(<500 \mu \mathrm{g} \cdot \mathrm{L}^{-}\right.$ $\left.{ }^{1}\right)$, Hypertrophication $\left(\geq 500 \mu \mathrm{g} \cdot \mathrm{L}^{-1}\right)$ [23]. Microcystis aeruginosa culture a few days later increase to the logarithmic phase, taking a certain amount of concentrated algae liquid diluted by BG 11 medium. The concentration of chlorophyll a is between $50 \mu \mathrm{g} \cdot \mathrm{L}^{-1}$ and $500 \mu \mathrm{g} \cdot \mathrm{L}^{-1}$, in order to simulate high algae-laden water, and then package one liter of algae liquid in every flask. Training two days under the same culture conditions in the incubator, and found no abnormality for the test to be used.

\section{B. Mn-Cu reagent preparation}

Reserving solution of copper reagent A: a certain amount of copper chloride powder weighted up accuracy, placed with the quantitative concentrated hydrochloric acid in the test tube shaken, acidification, to be completely dissolved, then switch to volumetric flack;

Reserving solution of manganese reagent $\mathrm{B}$ : A certain amount of permanganate dissolved in water to form a fixed concentration of potassium permanganate solution;
The reserving solution of A and B prepared in advance is mixed in different ratio to prepare the manganese copper compound algaecide, i.e., MCC.

\section{Methods}

Take a few samples prepared, dose in different ratio of MCC manganese copper compound algaecide respectively. Three bottles left without dosages, determine the average index as control. The index of supernatant are determined after dosing, in order to investigate the effect of MCC on algae removal. The value of spectrophotometry at $420 \mathrm{~nm}$ and chlorophyll a are representative of the concentration of algae cells [24]. Spectrometric determination $\mathrm{OD}_{420}$ and chlorophyll a by using Spectrophotometer 7205 . Turbidity determined by Turb350IR, pH value determined by pH Testr 10 .

It is generally believed that the algaecide with a long period of efficacy if algae cells will not re-grow after dosing $15 \mathrm{~d}$; otherwise, is a short effective period algaecide [25]. Base on the study of the optimum dosage ratio, the suitable ratio is selected as the experimental dosage of the MCC.All index were determined on scheduled time for more than $15 \mathrm{~d}$, in order to assess the effective period Length of the MCC.

\section{RESULTS AND DISCUSSIONS}

\section{A. Different MCC composited ratio}

\section{- Removal effect on turbidity}

Turbidity removal effects are investigated at $1 \mathrm{st}, 3 \mathrm{rd}, 7$ th and 10th days respectively after dosing copper reagent (A) and manganese reagent $(\mathrm{B})$ with ratio of $0.5: 1,1: 1,1.5: 1,2: 1$ and 2.5:1, compared with blank sample with no reagent dosage. The result on turbidity removal effect of MCC is shown in Fig.1.

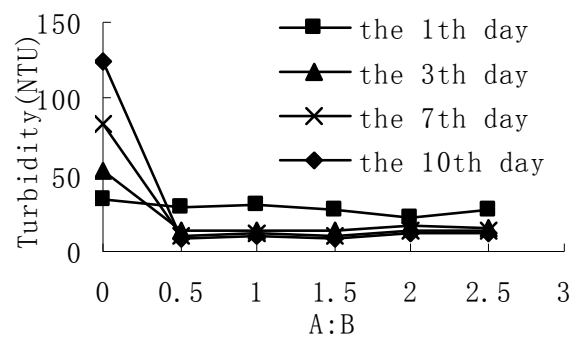

Figure 1. Turbidity removal with different ratio of $M C C$ dosage

Turbidity is decreased with increased reaction time of MCC and Microcystis aeruginosa liquid, in different ratio condition, as is shown in Fig.1. The turbidity has little change after reaction time of one week. The minimum turbidity is appeared at the 10th days after MCC dosing at the A and B ratio of 1.5:1, while the turbidity is decreased from $27.26 \mathrm{NTU}$ to $8.77 \mathrm{NTU}$ with removal rate of $67.82 \%$. Because the number of algae cell in the water can be reflected with turbidity, it can be found that MCC has a good algae removal effect.

- Removal Effect on $\mathrm{OD}_{420}$ 
The variation of $\mathrm{OD}_{420}$ with different ratio of $\mathrm{MCC}$ dosage is described in Fig.2. It can be seen that $\mathrm{OD}_{420}$ value is decreased in different degree after MCC dosing. The most obvious decrease is happened at the $7^{\text {th }}$ day with the $\mathrm{OD}_{420}$ value from 0.109 to 0.024 and the removal rate of $77.98 \%$. The $\mathrm{OD}_{420}$ value at the $10^{\text {th }}$ day is increased slightly compared with that at $7^{\text {th }}$ day. This phenomenon may be caused by part of died algae cell shells floating up from the bottom, or re-growth of algae cells causing the absorbance increase, which needs to be testified by further research.

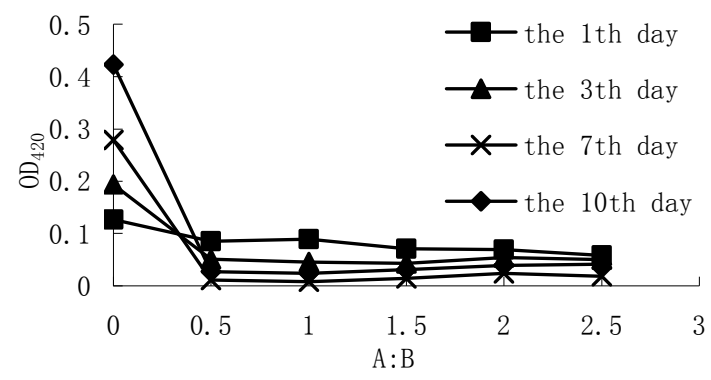

Figure 2. Variation of $\mathrm{OD}_{420}$ with different ratio of $M C C$ dosage

- Chlorophyll a removal efficiency

Chlorophyll $a$ is an important index to evaluate the growth of algae, and removal rate of chlorophyll $a$ can reflect the removal effect of algae. From Fig. 3 it can be seen that after 7 days removal rate of chlorophyll $a$ all exceed $85 \%$, at the $10^{\text {th }}$ day the variation of chlorophyll $a$ removal rate tends to be low, the rates are respectively $96.77 \%, 97.04 \%, 96.35 \%$, $96.70 \%, 96.74 \%$. It can be safely deduced that MCC has a obvious removal effect on algae.

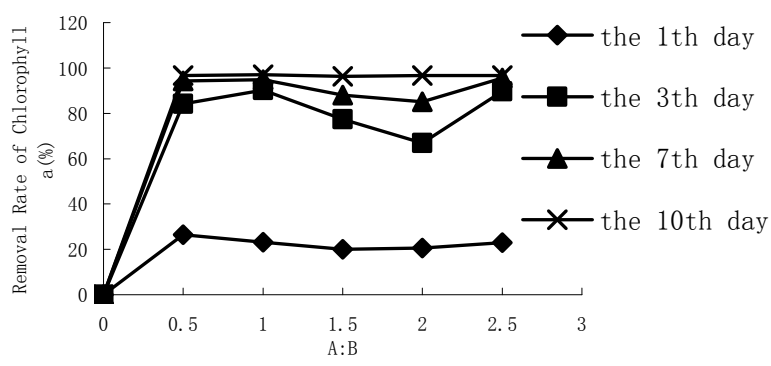

Figure 3. Chlorophyll a removal with different ratio of MCC dosage

The results above show that a good removal effect can be achieved when the ratio of copper $\mathrm{A} /$ manganese $\mathrm{B}$ is $0.5 \sim$ $1.5: 1$, but continuing to increase the dosage of A can not make a obviously better effect. As a result, the optimal ratio of copper A and manganese $\mathrm{B}$ is $0.5 \sim 1.5: 1$.

- Influence of MCC on $\mathrm{pH}$

As the copper reserving solution prepared is acid, it's need to study the influence on the value of $\mathrm{pH}$ using $\mathrm{MCC}$ to remove alga.Fig. 4 shows the variation of $\mathrm{pH}$ of water sample after adding MCC, from which it is seen that algae in blank sample are at log phase, grow vigorously and release some kind of alkaloid, which can make the $\mathrm{pH}$ increase continuously, $\mathrm{pH}$ is up to 10.81 at the 10th day. After adding MCC, $\mathrm{pH}$ has a little decrease as the dosage of copper A rises. Only the one whose ratio is $2.5: 1$ has a $\mathrm{pH}<7$, the others keeps at $7 \sim 8$, and alike with the BG 11 culture medium. But from Fig.1, Fig.2 and Fig.3 can be found that the optimal ratio of $\mathrm{MCC}$ and its removal effect have no liner relationship with the variation of $\mathrm{pH}$. So the variation of $\mathrm{pH}$ is not a key factor during the $\mathrm{MCC}$ removing algae. In addition, the algae cells decrease induced by algae dying making the $\mathrm{pH}$ tending to be neutral. So $\mathrm{pH}$ can be used as an indicator index during the treatment of high algae-laden water.

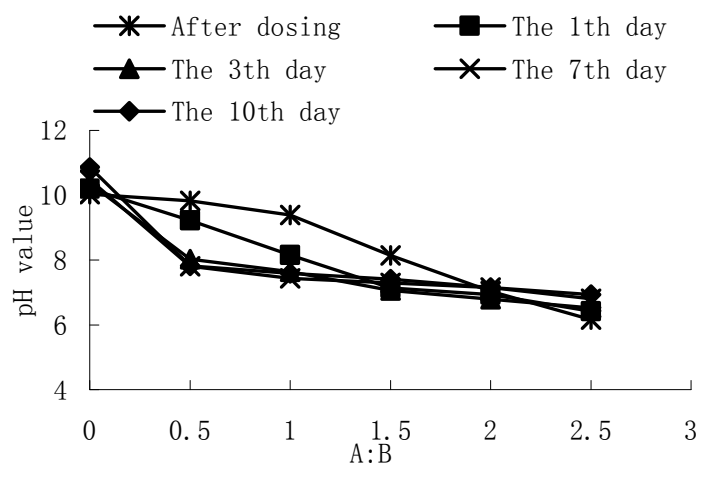

Figure 4. Variation of $\mathrm{pH}$ value

\section{B. Effective period of MCC}

Fig.5, Fig.6 and Fig.7 study the change of turbidity, $\mathrm{OD}_{420}$ and chlorophyll a separately under the condition of different acting time when MCC ratio remains 1:1.It shows that removal effect of turbidity and chlorophyll a decrease continuously as the acting time prolonged, and the minimum comes up at the $16^{\text {th }}$ day with NTU 6.16 and chlorophyll a $1.048 \mu \mathrm{g} \cdot \mathrm{L}-1$, the removal rate reached $77.40 \%$ and $99.48 \%$ separately. While the minimum of $\mathrm{OD}_{420}(0.018)$ appeared at the $7^{\text {th }}$ day after the administration, then had a little rise. The reason why $\mathrm{OD}_{420}$ would have a little rise may be that MCC lost its effect after 1 week so the residual algae cells re-grow; the other reason is that the died algae cells floating up from the bottom cause the value increase. It can also be found in Fig.5 and Fig.7 that chlorophyll a and turbidity is keeping decreasing from the $7^{\text {th }}$ to the $16^{\text {th }}$ day after the administration, that's to say MCC has a good removal effect. As a result, the re-growth of algae cells when MCC lost its effect is not the reason why $\mathrm{OD}_{420}$ had a little rise after administrating 7d.In a word, MCC still had capability to remove algae after dosing $15 \mathrm{~d}$, and algae cells didn't reincrease, so MCC has a relative long effect period.

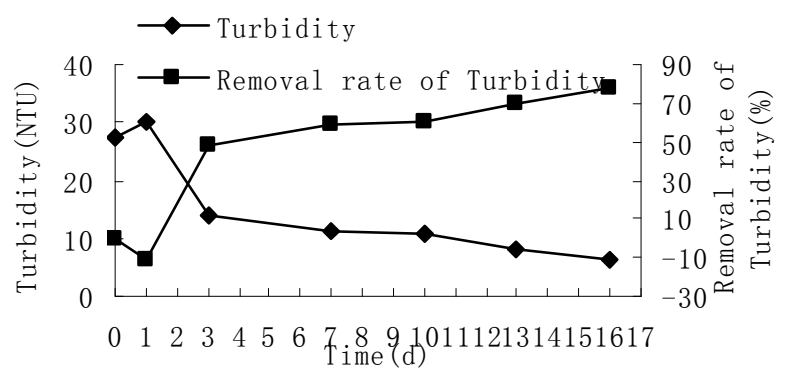

Figure 5. Effect on turbidity of $M C C$ reactive time 


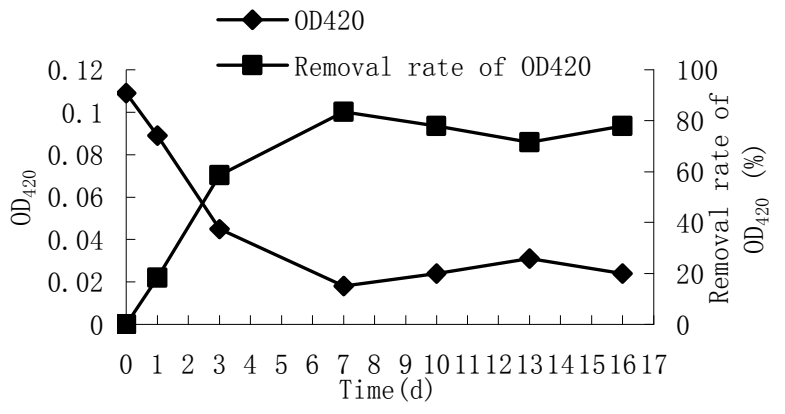

Figure 6. Effect on OD420 of MCC reactive time

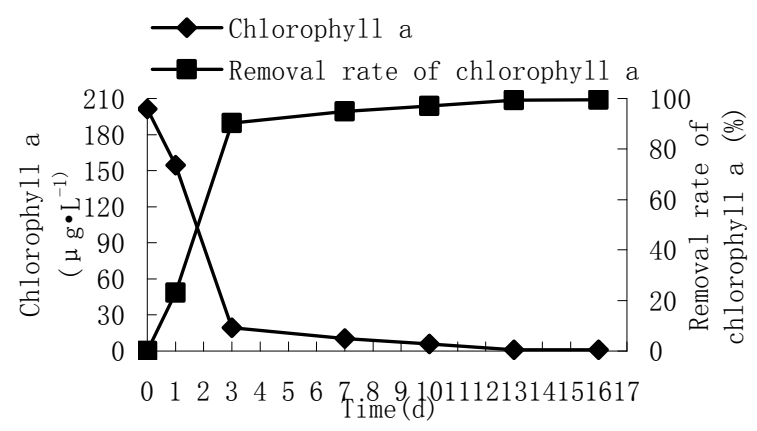

Figure 7. Effect on chlorophyll a of $M C C$ reactive time

\section{Mechanism discussion}

MCC is a new-style algaecide, its mechanism hasn't been covered yet. Cuprous chloride can form $\mathrm{H}_{3} \mathrm{O}^{+} \mathrm{CuCl}^{2-}$ in dense hydrochloric acid and these complex ions can dissolve in water. Furthermore, as the precursor of copper oxychloride, cuprous chloride solution can be oxidized in the air, the equation is as below:

$$
6 \mathrm{CuCl}+3 / 2 \mathrm{O}_{2}+3 \mathrm{H}_{2} \mathrm{O} \rightarrow 2 \mathrm{Cu}_{3} \mathrm{Cl}_{2}(\mathrm{OH})_{4}+\mathrm{CuCl}_{2}
$$

Permanganate have oxidation effect, they can produce hydrated manganese dioxide which has abundant surface hydroxyl groups, large specific surface area and significant coagulation efficiency [26] by reacting with reducing substances. One-valence cuprous ion has reducibility, it may react with permanganate to generate hydrated manganese dioxide. The turbidity increased instead of decreasing in Fig.5 may be caused by hydrated manganese.

Thus it can be speculated that the mechanism of MCC removing algae is probably because the permanganate oxidizing stimulating the cell wall of algae cells rather than destroy the frond. Cuprous ions dissolved in acid form complex ions; and some cuprous ions are oxidized by permanganate, generating hydrated manganese dioxide which has large specific surface area and can adsorb algae cells to sink. These complex ions and divalent enter the inside and kill cells directly. Because MCC is a newly developed algaecide, its mechanism still needs to be testified through a lot of further studies.

\section{CONCLUSIONS}

MCC (composed of permanganate and cuprous chloride) has a significant removal effect on Microcystis aeruginosa, Optimum ratio of copper reagent $\mathrm{A}$ and manganese reagents $\mathrm{B}$ was $0.5-1.5: 1$. Removal rate of turbidity, $\mathrm{OD}_{420}$ and chlorophyll a were $67.82 \%, 77.98 \%$ and $97.04 \%$ respectively during 10 days of MCC dosing.

MCC is a long effective period algaecide. Turbidity and chlorophyll a were reduced to $6.16 \mathrm{NTU}$ and $1.048 \mu \mathrm{g} \cdot \mathrm{L}^{-1}$, with removal rate of $77.4 \%$ and $99.48 \%$ after MCC dosing of 16 days. $\mathrm{pH}$ value of water samples was reduced with increased ratio of copper reagent within MCC. When composited ratio is $0.5-1.5: 1 \mathrm{pH}$ value is 7-8.

This study laid the foundation for research and development of the new algaecide. As a newly developed algaecide, MCC has broad prospects. However, a lot of research should be done to study its mechanism and application.

\section{REFERENCE :}

[1] [1] Plummer, J.D., Edzwald, J.K., 2001. Effect of ozone on algae as precursors for trihalomethane and haloacetic acid. Environ.Sci. Technol. 35 (18), 3661-3668

[2] [2] Schmidt, W., Hambsch, B., Petzoldt, H., 1998. Classification of algogenic organic matter concerning its contribution to the bacterial regrowth potential and by-products formation.Water Sci. Technol. 37 (2), 91-96.

[3] Oliver, B.G., Shindler, D.B., 1980. Trialomethanes from the chlorination of aquatic algae. Environ. Sci. Technol. 14 (12), 1502-1505.

[4] [4] Jochimsen EM, Carmichael WW. Liver failure and death following exposure to microcystin toxins at a dialysis center in Brazil. N Engl J Med, 1998, 338: $873-878$.

[5] [5] Falconer IR. Toxic cyanobacterial bloom problems in Australian waters: risks and impacts on human health.Phycologia 2001, 40:228233.

[6] [6] Zimba PV, Khoo L, Gaunt PS, Brittain S, Carmichael WW Confirmation ofcatfish, Ictalurua Punctatus (Rafinesque), mortality from Microcystis toxins. Fish Dis 2001, 24:41-47.

[7] [7] Anderson, D.M., 1997. Turning back the harmful red tide. Nature $388,513 \mathrm{e} 514$

[8] [8] Ingrid C, Jamie B. Toxic cyanobacteria in water. London and New York.E\&FN Spon Publisher, 1999.

[9] [9] Watanabe MF, Rugallf B. Toxic microcystis.Boca Raton, CRC Press.1996:35.

[10] [10] Yan, H., Pan, G., Zou, H., Song, L., Zhang, M.M., 2004. Effects and nitrogen forms on the production of cyanobacterial toxin Microcystin-LR by an isolated Microcystis aeruginosa. Journal of Environmental Science and Health, Part A Environmental Science and Engineering and Toxic and Hazardous Substance Control 39, 2993 3003.

[11] [11] Chorus, I., Bartram, J., 1999. Toxic Cyanobacteria in Water. F \& FN Spon Publisher, London.

[12] [12] Environmental Protection Agency of China, 2000. Chinese environmental annual reports of 2000. Journal of Environmental Protection 7, 1-6 (in Chinese).

[13] [13] Yin PH, Yu QM, Jin B, et al. Biosorption removal of cadmium from aqueous solution by using pretreated fungal biomass cultured from starch water. Water Research, 1999, 33(8):1960-1963.

[14] [14] Angeline K Y Lam, Ellie E Prepes, David Spink et al. Chemical Control of Hepatotoxic Phytoplankton Blooms : Implication for Human Health[J]. Water Research, 1995, 29(8):1845 - 1854. 
[15] [15] Lam, A.K.Y., Prepas, E.E., Spink, D., Hrudey, S.E., 1995.Chemical control of hepatotoxic phytoplankton blooms: implications for human health. Water Res. 29 (8), 1845-1854.

[16] [16] J.J. Chen and H.H. Yeh, The mechanisms of potassium permanganate on algae removal, Water Res., 39 (2005) 4420-4428.

[17] [17] B. Petrusevski, A.N.V. Breemen and G. Alaerts,Effect of permanganate pre-treatment and coagulationwith dual coagulants on algae removal indirect filtration. Water SRT-Aqua, 45 (1996)316-326.

[18] [18] Ma, J., Graham, N., Li, G., 1997. Effect of permanganate preoxidation in enhancing the coagulation of surface waterlaboratory case studies. Water Suppl.: Res. Technol.-AQUA 46 (1), 1-10.

[19] [19] Petruševski, B., Van Breemen, A.N., Alaerts, G., 1996. Effect of permanganate pre-treatment and coagulation with dual coagulants on algae removal in direct filtration. Water Suppl.: Res. Technol.-AQUA 45 (5), 316-326.

[20] [20] Kemp, H.T., Fuller, R.G., Davidson, R.S., 1966. Potassium permanganate as an algicide. J. Am. Water Works Assoc. 58(2), 255263.
[21] [21] Cleasby, J.C., Baumann, E.R., Black, C.D., 1964. Effectiveness of potassium permanganate for disinfection. J. Am. Water Works Assoc. 56 (4), 466-474.

[22] [22] X.D.Huang,W.Z.Wu,D.S.Li and Z.S.Wang, Experimental Research on Chemical Pre-Oxidation for Eutrophic Water Source, Water \& Wastewater Engineering,2001, 27 (7) :7 - 81.

[23] [23] Q.J.Kuang,P.M.Ma,Z.Y.Hu and G.J.Zhou, Study on the evaluation and treatment of lake eutrophication by means of algae biology, Journal of Safety and Environment, 2005, 5 ( 2 ) : 87-91(in Chinese).

[24] [24] Sukenik A, Teltch B, Wachs A W, et al. Effect of oxidants on microalgal flocculation [J]. Water Research, 1987, 21(5): 533-539.

[25] [25] X.Ling, Research of the Removal of Phaeocystis Globosa Red Tide by the Chemical Means, Master Dissertation of Ji Dan University,Xia Men:2002(in Chinese).

[26] [26] W. Yang,X. Li, Y.L. Yang and G.B. Li,Preparation and Coagulation Characteristic of Hydrated Manganese Dioxide, China Wat.Was., 2006,22 ( 15) : 37 -39(in Chinese). 